\title{
A Simple Nonlinear and End-Member-Free Approach for Obtaining Ocean Remineralization Patterns ${ }^{\circ}$
}

\author{
Patricia De La Fuente And Josep L. Pelegrí \\ Institut de Ciències del Mar, Consejo Superior de Investigaciones Científicas, Barcelona, Spain \\ ANTONIO CANEPA \\ Escuela de Ciencias del Mar, Pontificia Universidad Católica de Valparaíso, Valparaíso, Chile \\ MARC GASSER \\ Institut de Ciències del Mar, Consejo Superior de Investigaciones Científicas, Barcelona, Spain
}

FRANCISCO DOMÍNGUEZ

DC Servicios Ambientales, Santa Cruz de Tenerife, Spain

CÈlia MARrasé

Institut de Ciències del Mar, Consejo Superior de Investigaciones Científicas, Barcelona, Spain

(Manuscript received 13 May 2017, in final form 22 August 2017)

\begin{abstract}
The variability of a biogeochemical property in the ocean is the outcome of both nonconservative (such as respiration and photosynthesis) and conservative (mixing of water masses with distinct concentrations at origin) processes. One method to separate both contributions is based on a multiple regression of the biogeochemical property in terms of temperature $\theta$ and salinity $S$ as conservative proxies of water masses. This regression delivers the variability related to the conservative fraction and hence allows for identifying the residual as the biogeochemical anomaly. Here, the standard multiple linear regression (MLR) method, which assumes that water masses mix locally and linearly, is compared with a nonlinear polynomial regression (PR) over the entire $(\theta, S)$ space. The PR method has two important advantages over MLR: allows for simultaneous nonlinear mixing of all water masses and does not require knowing the end-member water types. Both approaches are applied to data along $7.5^{\circ} \mathrm{N}$ in the equatorial Atlantic Ocean, and the biogeochemical anomalies are calculated for humic-like fluorescent dissolved organic matter, apparent oxygen utilization, and nitrate-all of them related through in situ remineralization processes. The goodness of both approaches is assessed by analyzing the linear dependence and the coefficient of correlation between the anomalies. The results show that the PR method can be applied over the entire water column and yet retains the local variability associated with nonconservative processes. The potential of the PR approach is also illustrated by calculating the oxygen-nitrate stoichiometric ratio for the entire $7.5^{\circ} \mathrm{N}$ transatlantic section.
\end{abstract}

\section{Introduction}

The dissolved organic matter (DOM) in the ocean is represented by diverse pools with different biological

Supplemental information related to this paper is available at the Journals Online website: https://doi.org/10.1175/JTECH-D17-0090.s1.

Corresponding author: J. L. Pelegrí, pelegri@icm.csic.es lability, which can be conceptually divided into labile (residence time of minutes to days), semilabile (days to months), semirefractory (years to decades), and refractory (centuries to millennia) (Carlson et al. 2010; Catala et al. 2015; Hansell 2013 and references therein; Yamashita and Tanoue 2008). Marine DOM is the largest active reservoir of reduced carbon on Earth's surface (Hedges et al. 1997), and most of the DOM in the dark ocean (waters deeper than $200 \mathrm{~m}$ ) is refractory DOM (RDOM), with a pool of about $630 \mathrm{PgC}$ (Hansell 2013). 
A fraction of the RDOM is spectroscopically characterized through the emission of fluorescence at the excitation/emission wavelengths that distinguish humic substances when irradiated with ultraviolet; this RDOM fraction is named humic-like fluorescent DOM (FDOM) (Coble 2007, 1996). In situ FDOM production is a key process for maintaining the oceanic pool of optically active RDOM at centennial and millennia time scales (Catala et al. 2015; Yamashita and Tanoue 2008). Further insight into FDOM production will help advance our knowledge on RDOM cycling and its role in carbon sequestration into the deep ocean.

A number of studies have endorsed the idea that FDOM is mostly produced in situ via heterotrophic oxidation of organic matter in the dark ocean: this is based on a significant and positive association between FDOM and both apparent oxygen utilization (AOU) and nutrient salts (nitrate $\mathrm{NO}_{3}$ and phosphate $\mathrm{PO}_{4}$ ) that changes with water mass (Álvarez-Salgado et al. 2013; Catala et al. 2015; Chen and Bada 1992; De La Fuente et al. 2014; Hayase and Shinozuka 1995; Hayase et al. 1989; Jørgensen et al. 2011; Yamashita and Tanoue 2008; Yamashita et al. 2007).

Different statistical approaches are commonly used to obtain the ratios of FDOM production to oxygen depletion and inorganic-nutrients generation. The most usual is through simple regression models between the biogeochemical variables (Chen and Bada 1992; Hayase and Shinozuka 1995; Hayase et al. 1989; Jørgensen et al. 2011; Yamashita and Tanoue 2008; Yamashita et al. 2007). However, an important bias in the calculation of the biogeochemical ratios is introduced in those water masses with a high initial content of FDOM, acquired through river input of terrestrial humic compounds in the area of source water formation. For instance, a high amount of terrestrial organic matter is released from the continents to those regions where North Atlantic Deep Water (NADW) is formed. Jørgensen et al. (2011) found a significant and high correlation between FDOM and AOU for the dark global ocean but only when omitting the NADW from the linear regression model. In contrast, Yamashita and Tanoue (2008) found a high and significant relationship between FDOM and AOU for the deep Pacific Ocean (depths over $1000 \mathrm{~m}$ ), where mixing is small and the initial content of FDOM in the source water is low.

The abovementioned simple regression models assume that all of the data variability is only due to biological controls, neglecting any effect associated with the mixing of water masses with distinct contents at origin (Carlson et al. 2010; Reinthaler et al. 2013; Schneider et al. 2005). However, the relationship between any pair of nonconservative parameters indeed depends upon 1) the conservative mixing of source waters with different contents and 2) the nonconservative biological processes that take place since the water mass formation region (ÁlvarezSalgado et al. 2013; Castro et al. 1998, 2006; De La Fuente et al. 2014; Pérez et al. 1993, 1998, 2001; Reinthaler et al. 2013).

Statistical methods may be used to isolate the variability associated with both mixing and nonconservative biological processes. These methods are based on the idea that mixing of water masses has the same effect on both conservative and nonconservative properties. Hence, the evolution of the conservative fraction of a biogeochemical property may be inferred from the covariance between these biogeochemical data and both salinity $S$ and potential temperature $\theta$ as conservative proxies of water mass; that is, the conservative fraction is determined from a regression model as a function of $(\theta, S)$. The resultant anomalies, calculated as the observed values minus the modeled values, should reflect the variability associated with biological processes.

The challenge is to use the best-possible regression model; that is, a data-fit model that can properly track the conservative evolution of the water masses without removing the biogeochemical anomalies. One simple approach is to assume that the water parcel results from the linear mixing of two or more source water types (SWT; called end-members) in a conservative $\theta-S$ space, a physical process that should equally transform the conservative and nonconservative properties. In particular, since any water sample in the conservative $\theta-S$ space can be expressed as the linear combination of three $(\theta, S)$ end-members, the corresponding biogeochemical concentration should emerge from a multiple linear correlation with $S$ and $\theta$ (e.g., Álvarez-Salgado et al. 2013). The linear mixing approach has been extensively used for determining the distribution of water masses in the World Ocean, either using the classical method of mixing triangles when only temperature and salinity are involved (Mamayev 1975) or employing different varieties of the optimum multiparameter method when other properties are also considered (e.g., Mackas et al. 1987; Llanillo et al. 2012, 2013).

Despite the extensive application of the classical mixing method to infer the conservative fraction of the biogeochemical variables, the assumption of conservative local and lineal mixing in the $\theta-S$ space is not necessarily true. There is no justification behind the assumption that only three water types participate in the composition of any given water parcel, and there is no unique solution for the linear mixing of three conservative properties (temperature, salinity, and mass) with more than three end-members. Further, ocean mixing is not isotropic in the $\theta-S$ space as, in the absence of convective processes, it takes place preferentially along isopycnals. Therefore, the conservative fraction of any biogeochemical variable may as well be proportional 


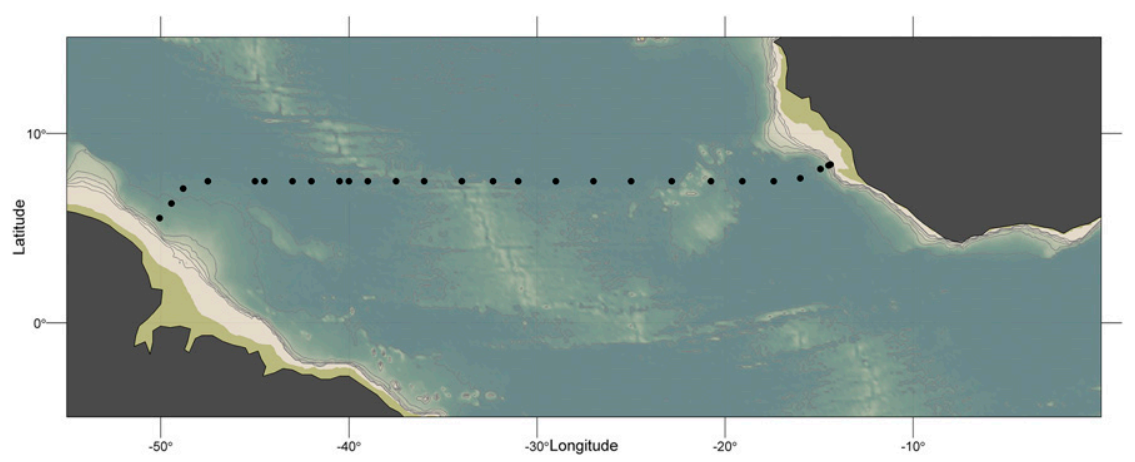

FIG. 1. Study area showing the biogeochemical stations along $7.5^{\circ} \mathrm{N}$ during the MOC2-Equatorial cruise.

to a nonlinear function of $\theta$ and $S$. Recently, through a multiple nonlinear regression for both FDOM and AOU as a function of temperature and salinity over the entire $(\theta, S)$ space, De La Fuente et al. (2014) found a significant correlation between the FDOM and AOU anomalies for the dark equatorial Atlantic Ocean.

In this study we explore the goodness of linear-local and nonlinear-global methods to obtain the nonconservative anomalies. All these approaches remove the information associated with conservative mixing of source water types through a multiple regression of the nonconservative property with $S$ and $\theta$. However, while one approach is based on the local linear mixing of a maximum of three source water masses (Carlson et al. 2010; Castro et al. 2006; Li and Peng 2002; Nieto-Cid et al. 2005; Schneider et al. 2005), the other one focuses on fitting high-order polynomial models over the entire $\theta-S$ space (De La Fuente et al. 2014).

For our analysis we use the dataset obtained during a cruise carried out in the equatorial Atlantic Ocean in April-May 2010. The slopes, coefficients of correlation, and the significance of the relationships between the anomalies obtained from both approaches are evaluated. The differences in these relationships are then examined, and the strengths and weaknesses of both methods are discussed. Finally, the potential of the nonlinear-global method is also illustrated, calculating the stoichiometric ratio between oxygen and nitrate.

\section{Measurements}

Measurements were obtained from 26 full-depth hydrographic stations during the MOC2-Equatorial cruise, carried out along $7.5^{\circ} \mathrm{N}$ in the equatorial Atlantic Ocean on board R/V Hespérides between 20 April and 13 May 2010 (Fig. 1); data are available at the Carbon Hydrographic Data Office (https://cchdo.ucsd.edu/ cruise/29HE20100405). Continuous salinity and temperature profiles were recorded with a Sea-Bird 911plus CTD system attached to a 24 Niskin rosette sampler. Water samples at 24 levels were used to determine the concentrations of dissolved oxygen (DO), nitrate $\left(\mathrm{NO}_{3}\right)$, and FDOM. For this study we have considered only those levels deeper than $200 \mathrm{~m}$ (ocean interior).

DO water samples were taken in sealed flasks $(250 \mathrm{~mL})$ and kept in the dark for $24 \mathrm{~h}$ until their analysis. DO was determined using an automated potentiometric modification of the original Winkler method following WOCE standards (Culberson 1994) with a precision of $\pm 0.5 \mu \mathrm{mol} \mathrm{kg}^{-1}$. AOU is defined as the deficit of oxygen concentration relative to its atmospheric saturation value under equal physical conditions (Benson and Krause 1984; Weiss 1970).

$\mathrm{NO}_{3}$ water samples were collected in stoppered polypropylene conical centrifuge tubes $(15 \mathrm{~mL})$. The samples were fitted directly onto the AutoSampler of a four-channel Technicon Bran+Luebbe AutoAnalyzer II (AAII) for determining nitrates and nitrites by continuous flow analysis (Tréguer and Le Corre 1975).

FDOM water samples were collected in acidclean glass bottles of $250 \mathrm{~mL}$ and analyzed on board within $2 \mathrm{~h}$ after sampling at the ship laboratory temperature (ca. $20^{\circ} \mathrm{C}$ ) with a PerkinElmer LS spectrometer equipped with a xenon discharge lamp. Slit widths were $10 \mathrm{~nm}$ for the excitation and emission wavelengths. Measurements were performed in a 1-cm quartz cell, and Milli-Q water was used as a reference blank. The fluorescence intensity was measured at fixed excitation/emission wavelengths of 340/440 nm, F(340/440), characteristic of humic-like substances (Coble 1996), and normalized to Raman units (RU) according to Lawaetz and Stedmon (2009).

\section{Methods}

As exposed in the introduction, almost all previous studies on regeneration ratios assume that the conservative fraction of a biogeochemical variable arises as a linear combination of three end-members. The essence 


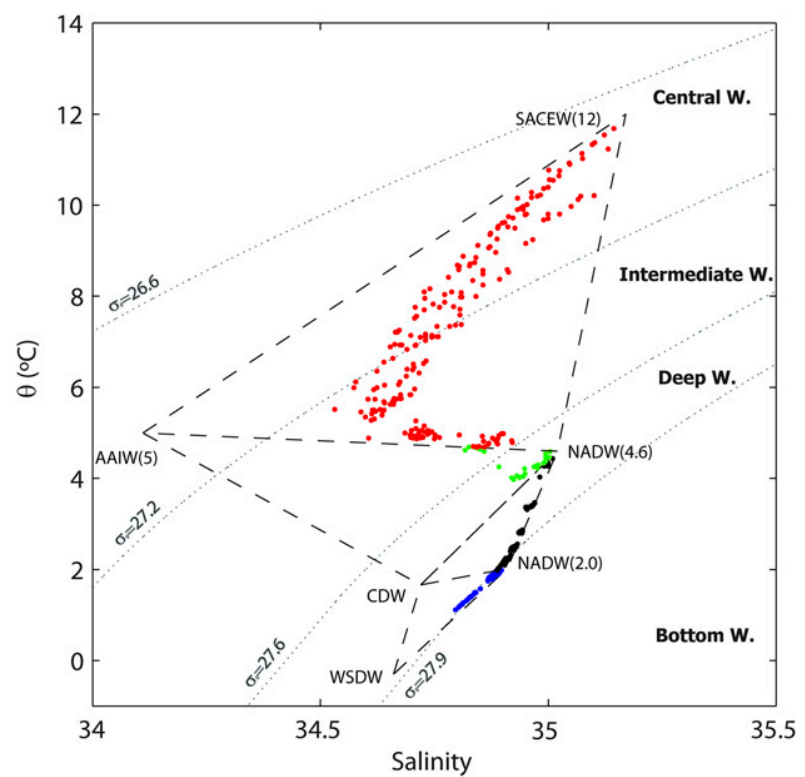

FIG. 2. The $\theta-S$ diagram with the biogeochemical stations data, split in mixing triangles as follows: NADW(2.0)-CDW-WSDW (blue dots), NADW(4.6)-NADW(2.0)-CDW (black dots), AAIW(5)NADW(4.6)-CDW (green dots), and SACEW(12)-AAIW(5)NADW(4.6) (red dots). The isopycnals $\left(\sigma_{\theta}\right)$ 26.6, 27.2, 27.6, and 27.9 (gray lines), approximately corresponding to the isoneutrals $\left(\gamma^{n}\right)$ $26.65,27.3,27.8$, and 28.12 , are used to divide the water column into the following isoneutral strata: central (26.65-27.3), intermediate (27.3-27.8), deep (27.8-28.12), and bottom (>28.12).

of the approach may be understood by considering the closed system of equations that represents any data point as the conservative combination of three water types:

$$
\begin{aligned}
& \theta=x_{a} \theta_{a}+x_{b} \theta_{b}+x_{c} \theta_{c}, \\
& S=x_{a} S_{a}+x_{b} S_{b}+x_{c} S_{c}, \\
& 1=x_{a}+x_{b}+x_{c} .
\end{aligned}
$$

For any data point in the $(\theta, S)$ space that falls inside a triangle closed by the end-members $\left(\theta_{a}, S_{a}\right)$, $\left(\theta_{b}, S_{b}\right)$, and $\left(\theta_{c}, S_{c}\right)$, there is one unique solution for the end-member fractions $x_{a}, x_{b}, x_{c}$; for example, $x_{a}=x_{a}\left(\theta, S, \theta_{a}, \theta_{b}, \theta_{c}, S_{a}, S_{b}, S_{c}\right)$. For fixed properties of the end-members, this expression turns into a linear functional dependence $x_{a}=x_{a}(\theta, S)$. Hence, the conservative fraction of any property with concentration $Y$ that follows a linear combination of the values of the three end-members can be expressed as

$$
Y=x_{a}(\theta, S) Y_{a}+x_{b}(\theta, S) Y_{b}+x_{c}(\theta, S) Y_{c} .
$$

This is a linear expression of $\theta$ and $S$ that relies on the mixing of three end-members in the $(\theta, S)$ space, commonly calculated by adjusting the predictions to the data points in a least squares sense (sometimes including a
TABLE 1. Thermohaline characteristics of the SWTs from Álvarez et al. (2014).

\begin{tabular}{llrc}
\hline \hline \multicolumn{1}{c}{ SWT, full name } & SWT, abbreviated & $\theta\left({ }^{\circ} \mathrm{C}\right)$ & \multicolumn{1}{c}{$S$} \\
\hline $\begin{array}{l}\text { South Atlantic Central } \\
\text { Subequatorial Water }\end{array}$ & SACEW $(12)$ & 12.00 & 35.17 \\
$\begin{array}{l}\text { Antarctic Intermediate Water } \\
\text { Upper and Middle North }\end{array}$ & AAIW(5) & 5.00 & 34.11 \\
$\quad$ Atlantic Deep Water & NADW $(4.6)$ & 4.60 & 35.02 \\
$\begin{array}{l}\text { Lower North Atlantic Deep } \\
\quad \text { Water }\end{array}$ & NADW(2.0) & 2.02 & 34.91 \\
$\begin{array}{l}\text { Upper and Lower Circumpolar } \\
\text { Deep Water }\end{array}$ & CDW & 1.66 & 34.72 \\
Weddell Sea Deep Water & WSDW & -0.30 & 34.66 \\
\hline
\end{tabular}

regeneration or consumption term). However, mixing of more than three end-members or the existence of preferential mixing pathways, such as along isopycnals, will lead to nonlinear relations.

\section{a. $M L R$}

For each nonconservative response variable $Y$ - such as $\mathrm{F}(340 / 440)$, AOU, or $\mathrm{NO}_{3}$ - a multiple linear regression (MLR) model is applied in terms of the conservative thermohaline predictor variables $-S$ and $\theta$ (Carlson et al. 2010; Castro et al. 2006; Nieto-Cid et al. 2005; Schneider et al. 2005). All data in the $\theta-S$ plane are made to correspond to three end-member mixing triangles (Fig. 2), with the source water types as defined in Álvarez et al. (2014) (Table 1), ensuring that each observation is explained as a mixture of up to three source waters.

The biogeochemical variables are modeled as follows:

$$
\hat{Y}_{i k}=\alpha_{0 k}+\alpha_{1 k} S_{i k}+\alpha_{2 k} \theta_{i k},
$$

where $i k$ is the $i$ sample observation out of a total of $n k$ observations in the respective $k$ mixing triangle. For each $i k(\theta, S)$ pair, the anomaly from the model $\Delta Y_{i k}$ is obtained by subtracting the value estimated through the optimal model $\left(\hat{Y}_{i k}\right)$ from the observed value $\left(Y_{i k}\right)$ :

$$
\Delta Y_{i k}=Y_{i k}-\hat{Y}_{i k} .
$$

The unknown parameters $\left(\alpha_{0 k}, \alpha_{1 k}\right.$, and $\left.\alpha_{2 k}\right)$ are determined using an ordinary least squares (OLS) fitting, that is, minimizing the summed square of $\Delta Y_{i k}$.

For each mixing triangle and variable $[\mathrm{F}(340 / 440)$, $\mathrm{AOU}$, or $\mathrm{NO}_{3}$ ], the significance of the model is tested through the $\mathrm{F}$ statistic $[\operatorname{Pr}(>|\mathrm{F}|)$ with $p$ value $<0.01]$; the variance captured by the model is evaluated through the adjusted coefficient of determination, adjusted $r$ squared $\left(\right.$ adj- $\left.r^{2}\right)$ (Table S1, supplemental materials); and the significance of the estimated coefficients is tested through a Student's $t$ statistic [Pr $(>|t|)$ with $p$ value $<0.05]$. 


\section{b. $P R$}

An alternative approach consists of a multiple nonlinear polynomial regression (PR) between each nonconservative response variable $Y$ and the conservative thermohaline predictor variables for the entire $(\theta, S)$ space. De La Fuente et al. (2014) used a quadratic polynomial (PR2) to model the biogeochemical variable. It includes all linear and quadratic terms in $\theta$ and $S$, as well as a nonlinear dependence on the product of $\theta$ and $S$ :

$$
\hat{Y}_{i}=\alpha_{0}+\alpha_{1} S_{i}+\alpha_{2} \theta_{i}+\alpha_{3} S_{i}^{2}+\alpha_{4} \theta_{i}^{2}+\alpha_{5} \theta_{i} S_{i} .
$$

where $i$ is the sample observation out of a total of $n$ observations in the dataset. The anomalies are obtained through an expression analogous to Eq. (4):

$$
\Delta Y_{i}=Y_{i}-\hat{Y}_{i} .
$$

We expect that the higher the order of the polynomial, the better the data fit and the lower the anomalies. However, a high-order polynomial is not necessarily a good solution because each additional term may lead to a minimal improvement in the solution. A useful tool to ensure that these new high-order terms are meaningful is the Akaike information criterion (AIC), which rewards the goodness of fit (as assessed by the likelihood function) but penalizes the excess of parameters; so, the lower the AIC, the better the model (Zuur et al. 2009). Through a stepwise selection process that uses the AIC, we increase the complexity of the polynomial and come up with two new PR models; these models are particular cases of the full cubic polynomial (Table S2, supplemental materials) as explained next.

The second PR model (PR3) is similar to PR2 but with the cubic term in $\theta$ replacing the quadratic term in $S$ :

$$
\hat{Y}_{i}=\alpha_{0}+\alpha_{1} S_{i}+\alpha_{2} \theta_{i}+\alpha_{4} \theta_{i}^{2}+\alpha_{5} \theta_{i} S_{i}+\alpha_{7} \theta_{i}^{3} .
$$

The third PR model (PRcub) includes all quadratic and three cubic terms (this is the full cubic polynomial except for the $S^{3}$ term):

$$
\begin{aligned}
\hat{Y}_{i}= & \alpha_{0}+\alpha_{1} S_{i}+\alpha_{2} \theta_{i}+\alpha_{3} S_{i}^{2}+\alpha_{4} \theta_{i}^{2}+\alpha_{5} \theta_{i} S_{i} \\
& +\alpha_{7} \theta_{i}^{3}+\alpha_{8} S_{i} \theta_{i}^{2}+\alpha_{9} S_{i}^{2} \theta_{i} .
\end{aligned}
$$

For each of the abovementioned models, the unknown parameters $\left(\alpha_{i}\right)$ are determined using an OLS fitting, that is, minimizing the anomalies [Eq. (6)]. The significance of the model is tested through the F statistic $[\operatorname{Pr}(>|F|)$ with $p$ value $<0.01$ ], the variance captured by the model is evaluated through the adj- $r^{2}$ (Table S3, supplemental materials), and the significance of the estimated coefficients is tested through the Student's $t$ test $[\operatorname{Pr}(>|t|)$ with $p$ value $<0.05]$.

\section{c. Anomaly analysis}

\section{1) Definition of WATER STRATA}

To compare the behavior of all four models (MLR, PR2, PR3, and PRcub), the water column (depths greater than $200 \mathrm{~m}$ ) in the region of study is divided in four water strata (central, intermediate, deep, and bottom) that correspond to different isoneutral $\left(\gamma^{n}\right)$ ranges (San Antolín Plaza et al. 2012) (Fig. 2; see Table 1 for the nomenclature of the different water types). The mixing triangle defined by SACEW(12)-AAIW(5)-NADW(4.6) corresponds to central $\left(26.65>\gamma^{n}<27.3\right)$ and intermediate $\left(27.3>\gamma^{n}<\right.$ 27.8) waters (Álvarez et al. 2014; Arhan et al. 1998; San Antolín Plaza et al. 2012; Stramma and Schott 1999). The mixing triangles defined by AAIW(5)-NADW(4.6)CDW and NADW(4.6)-CDW-NADW(2.0) conform to deep waters, approximately delimited by the $27.8>\gamma^{n}<$ 28.12 isoneutral range, with a major contribution from NADW (Álvarez et al. 2014; San Antolín Plaza et al. 2012; Stramma and Schott 1999). The mixing triangle defined by WSDW-CDW-NADW(2.0) includes bottom waters $\left(\gamma^{n}>28.12\right)$, with a predominance of AABW (Álvarez et al. 2014; San Antolín Plaza et al. 2012; Stramma and Schott 1999). Computation of $\gamma^{n}$ is performed following McDougall and Barker (2011).

\section{2) BiogeOCHEMICAL SIGNIFICANCE OF THE ANOMALIES}

The biogeochemical anomalies- $\Delta \mathrm{F}(340 / 440), \Delta \mathrm{AOU}$, and $\Delta \mathrm{NO}_{3}$ - are determined using the MLR and PR approaches for the entire ocean, as well as for each water stratum. For each model, the relationships between each pair of anomalies are then calculated by means of a simple linear regression II [standard major axis (SMA)] that takes into account the variability of both variables. This includes the slope of the linear regression together with the corresponding adjusted correlation coefficient $\left(\operatorname{adj}-r^{2}\right)$ and the significance of the test $(p$ value $<0.05)$.

In this study we use the adj- $r^{2}$ for the biogeochemical anomalies in order to identify which model (MLR, PR2, PR3, and PRcub) best removes the conservative contributions. Under the assumption that all anomalies respond to related nonconservative processes (ÁlvarezSalgado et al. 2013; Catala et al. 2015; Chen and Bada 1992; De La Fuente et al. 2014; Hayase and Shinozuka 1995; Hayase et al. 1989; Jørgensen et al. 2011; Yamashita and Tanoue 2008; Yamashita et al. 2007), we expect that the model that best captures the conservative behavior will lead to anomalies that retain most of the variability associated with the biogeochemical processes, that is, will lead to the highest correlation among the anomalies. 
All statistical analyses are carried out with the statistical programming software $\mathrm{R}$, version 0.97 .551 , using the package "smatr" (Warton et al. 2012; https://cran.r-project.org/ web/packages/smatr/index.html).

\section{Results}

\section{a. Model analysis}

The MLR approach proposes that the physicochemical variability of a biogeochemical variable $(Y)$ is the outcome of the linear mixing of up to three water masses. For each mixing triangle and variable, Eq. (3) defines a plane in the three-dimensional space $(\theta-S-Y)$; in contrast, the PR methods predict a single and continuous surface for each variable, $Y=Y(\theta, S)$ (Figs. 3 and $\mathrm{S} 1$ in supplemental materials).

The MLR and the three PR models (PR2, PR3, and PRcub) are applied to $\mathrm{F}(340 / 440), \mathrm{AOU}$, and $\mathrm{NO}_{3}$. The projection of the triangular planes on the $\theta-S$ domain leads to the three-end-member mixing triangles concept, where any $\theta-S$ point belongs to one single triangle. However, the projection of the data to the other two planes, either $S=S(\theta, Y)$ or $\theta=\theta(S, Y)$, shows substantial overlapping between mixing triangles, particularly in the $S-Y$ plane (Figs. 3 and $\mathrm{S} 1$ in supplemental materials). This may be interpreted as indicative of a nonconservative contribution to the $Y$ variable, but it may also reflect the intrinsic limitations when choosing a maximum of three end-members for conservative mixing.

The model statistics-AIC, adj- $r^{2}$, and Fisher's $p$ value-are presented in Tables S1 and S3 (supplemental materials). These statistics show that all models are highly significant ( $p$ value $<0.001$ ), yet PR3 and particularly PRcub provide the highest adj- $r^{2}$ values.

\section{b. Anomaly analysis: Remineralization ratios}

Applying the MLR method to each individual stratum and applying the PR2, PR3, and PRcub methods to the entire ocean interior (Table S2, supplemental materials), we find the anomaly ratios to always be significant ( $p$ value $<0.05)$, except for the $\Delta \mathrm{F}(340 / 440)-\Delta \mathrm{NO}_{3}$ relationship in bottom waters when using the PR2 method (Tables 2-4). When considering the entire water column (depths greater than $200 \mathrm{~m}$ ), all methods except PRcub give similar slopes and adj- $r^{2}$ coefficients. When looking at the results of MLR, PR2, and PR3 per water stratum, all slopes and adj- $r^{2}$ are very much alike in the central and intermediate strata but show some significant differences in the deep and bottom strata (Tables 2-4). In these deep and bottom waters, PR3 gives the highest correlation coefficients and the values closest to the mean-depth values, except for $\Delta \mathrm{AOU}-\Delta \mathrm{NO}_{3}$ in bottom waters. In contrast, for most water strata PRcub leads to
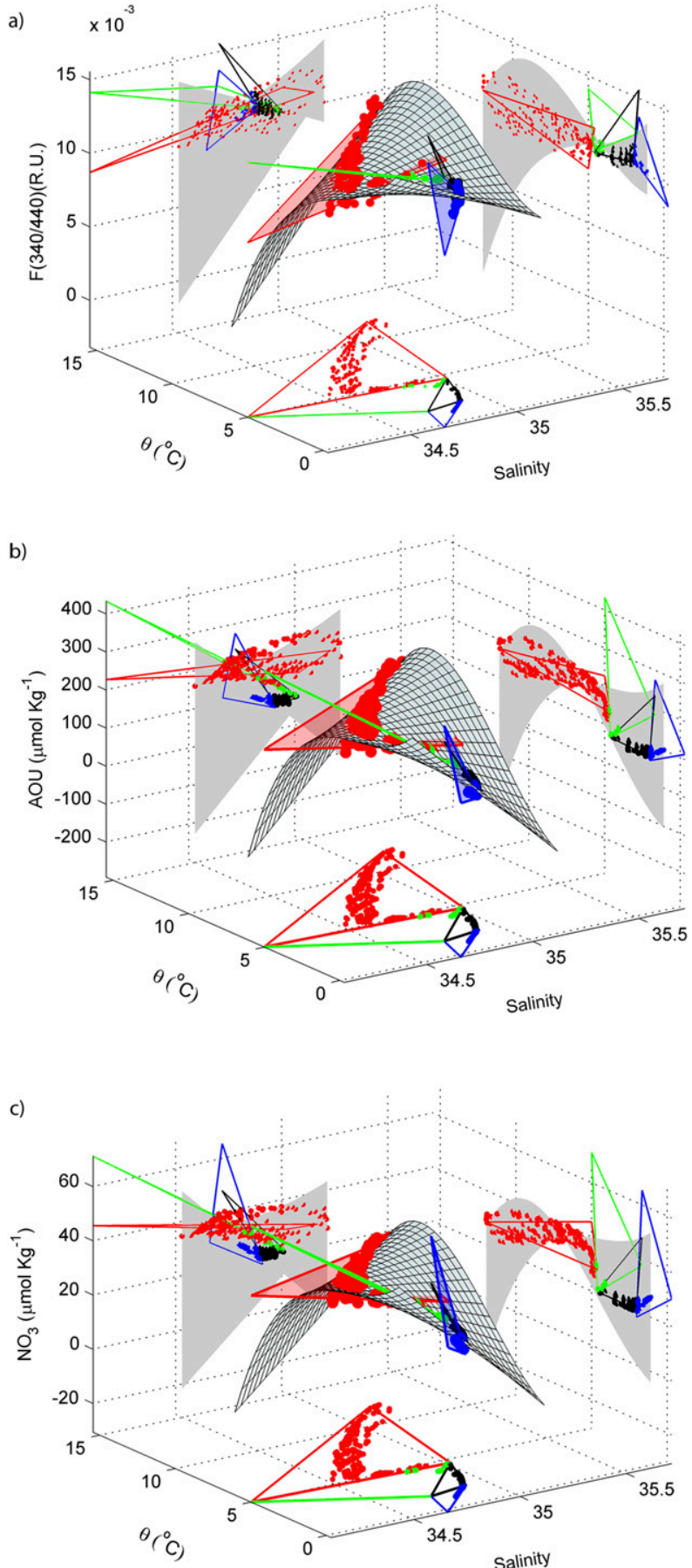

FIG. 3. (a) Three-dimensional representation of the PR3 (surface) and MLR (planes) predictions for $\mathrm{F}(340 / 440)$ as a function of $S$ and $\theta$; the colors of the lines and dots define the different planes used by MLR as follows: NADW(2.0)-CDW - WSDW (blue), NADW(4.6)-NADW (2.0)-CDW (black), AAIW(5)-NADW(4.6)-CDW (green), and SACEW(12)-AAIW(5)-NADW(4.6) (red). The $\theta-S$ diagram corresponds to the projection onto the bottom plane; similar projections are drawn on the $\mathrm{F}(340 / 440)-S$ and $\theta-\mathrm{F}(340 / 440)$ planes with the shaded area corresponding to the $2 \mathrm{D}$ projection on the respective surface. (b) As in (a), but using AOU rather than $\mathrm{F}(340 / 440)$. (c) As in (a), but using $\mathrm{NO}_{3}$ rather than $\mathrm{F}(340 / 440)$. 
TABLE 2. Relationship of $\Delta \mathrm{F}(340 / 440)$ with $\Delta$ AOU for the MLR, PR2, PR3, and PRcub methods, as deduced using an SMA regression. The slope of the linear regression (slope), the adjusted correlation coefficient $\left(\operatorname{adj}-r^{2}\right)$, the significance of the test ( $p$ value with $\alpha=0.05$ ), and the total sampling points $(n)$ are shown for the ocean interior and each water strata (central, intermediate, deep, and bottom). The slope is shown only for significant relationships $(p$ value $<0.05)$.

\begin{tabular}{|c|c|c|c|c|c|}
\hline \multicolumn{6}{|c|}{$\Delta \mathrm{F}(340 / 440)-\Delta \mathrm{AOU}$} \\
\hline Water strata & Approach & Slope $\left(\times 10^{-5}\right)$ & $\operatorname{adj}-r^{2}$ & $p$ value & $n$ \\
\hline \multirow[t]{4}{*}{ Ocean interior } & MLR & $2.9 \pm 0.1$ & 0.82 & $<0.001$ & 355 \\
\hline & PR2 & $3.1 \pm 0.1$ & 0.79 & $<0.001$ & 355 \\
\hline & PR3 & $3.5 \pm 0.1$ & 0.78 & $<0.001$ & 355 \\
\hline & PRcub & $4.1 \pm 0.1$ & 0.59 & $<0.001$ & 355 \\
\hline \multirow[t]{4}{*}{ Central } & MLR & $2.8 \pm 0.1$ & 0.92 & $<0.001$ & 96 \\
\hline & PR2 & $2.9 \pm 0.1$ & 0.92 & $<0.001$ & 96 \\
\hline & PR3 & $3.3 \pm 0.1$ & 0.90 & $<0.001$ & 96 \\
\hline & PRcub & $3.8 \pm 0.2$ & 0.81 & $<0.001$ & 96 \\
\hline \multirow[t]{4}{*}{ Intermediate } & MLR & $3.0 \pm 0.1$ & 0.80 & $<0.001$ & 102 \\
\hline & PR2 & $3.1 \pm 0.1$ & 0.79 & $<0.001$ & 102 \\
\hline & PR3 & $3.2 \pm 0.1$ & 0.76 & $<0.001$ & 102 \\
\hline & PRcub & $4.7 \pm 0.3$ & 0.52 & $<0.001$ & 102 \\
\hline \multirow[t]{4}{*}{ Deep } & MLR & $5.5 \pm 0.0$ & 0.31 & $<0.001$ & 127 \\
\hline & PR2 & $4.8 \pm 0.0$ & 0.57 & $<0.001$ & 127 \\
\hline & PR3 & $3.6 \pm 0.2$ & 0.60 & $<0.001$ & 127 \\
\hline & PRcub & $4.3 \pm 0.3$ & 0.47 & $<0.001$ & 127 \\
\hline \multirow[t]{4}{*}{ Bottom } & MLR & $9.7 \pm 0.1$ & 0.61 & $<0.001$ & 30 \\
\hline & PR2 & $9.5 \pm 0.0$ & 0.20 & $<0.001$ & 30 \\
\hline & PR3 & $6.4 \pm 0.4$ & 0.80 & $<0.001$ & 30 \\
\hline & PRcub & $3.9 \pm 0.7$ & 0.26 & $<0.01$ & 30 \\
\hline
\end{tabular}

slopes that are quite different from the other methods, with much lower adj- $r^{2}$.

The scattered plots of the biogeochemical anomalies help visualize the high correlation achieved by MLR, PR2, and PR3 (Figs. 4-6). The data points for the original variables appear clustered by water stratum; in contrast, the anomalies closely fall into one single regression line. Despite the similarity between all the methods, it is ostensible that the anomalies calculated by both MLR and PR3 remain closer to the regression line. It is worthwhile pointing out the high correlation between $\triangle \mathrm{AOU}$ and $\Delta \mathrm{NO}_{3}$ - in excess of 0.9 for MLR, PR2, and PR3 - which provides a mean slope for the entire ocean interior of $8.0 \pm 0.1$. This value is in fairly good agreement with the global-average 138:16 stoichiometric $-\mathrm{O}_{2}: \mathrm{N}$ ratio reported by Takahashi et al. (1985).

The abovementioned results confirm that PRcub is inadequate to retain the nonconservative signature. This model provides the best adjustment to the data, but the fit is so good that it gets rid of the variability caused by nonconservative processes. For this reason in the forthcoming discussion we have considered only the MLR, PR2, and PR3 models.
TABLE 3. As in Table 2, but for $\Delta \mathrm{F}(340 / 440)$ with $\Delta \mathrm{NO}_{3}$.

\begin{tabular}{|c|c|c|c|c|c|}
\hline \multicolumn{6}{|c|}{$\Delta \mathrm{F}(340 / 440)-\Delta \mathrm{NO}_{3}$} \\
\hline Water strata & Approach & Slope $\left(\times 10^{-4}\right)$ & $\operatorname{adj}-r^{2}$ & $p$ value & $\bar{n}$ \\
\hline \multirow[t]{4}{*}{ Ocean interior } & MLR & $2.3 \pm 0.1$ & 0.79 & $<0.001$ & 338 \\
\hline & PR2 & $2.6 \pm 0.1$ & 0.73 & $<0.001$ & 338 \\
\hline & PR3 & $2.8 \pm 0.1$ & 0.71 & $<0.001$ & 338 \\
\hline & PRcub & $2.9 \pm 0.1$ & 0.48 & $<0.001$ & 338 \\
\hline \multirow[t]{4}{*}{ Central } & MLR & $2.3 \pm 0.1$ & 0.92 & $<0.001$ & 91 \\
\hline & PR2 & $2.4 \pm 0.1$ & 0.92 & $<0.001$ & 91 \\
\hline & PR3 & $2.7 \pm 0.1$ & 0.92 & $<0.001$ & 91 \\
\hline & PRcub & $2.9 \pm 0.1$ & 0.75 & $<0.001$ & 91 \\
\hline \multirow[t]{4}{*}{ Intermediate } & MLR & $2.2 \pm 0.1$ & 0.77 & $<0.001$ & 98 \\
\hline & PR2 & $2.3 \pm 0.1$ & 0.76 & $<0.001$ & 98 \\
\hline & PR3 & $2.4 \pm 0.1$ & 0.70 & $<0.001$ & 98 \\
\hline & PRcub & $3.1 \pm 0.2$ & 0.39 & $<0.001$ & 98 \\
\hline \multirow[t]{4}{*}{ Deep } & MLR & $3.7 \pm 0.3$ & 0.14 & $<0.001$ & 119 \\
\hline & PR2 & $3.6 \pm 0.3$ & 0.40 & $<0.001$ & 119 \\
\hline & PR3 & $3.0 \pm 0.2$ & 0.50 & $<0.001$ & 119 \\
\hline & PRcub & $3.0 \pm 0.2$ & 0.36 & $<0.001$ & 119 \\
\hline \multirow[t]{4}{*}{ Bottom } & MLR & $8.7 \pm 2.0$ & 0.30 & $<0.01$ & 30 \\
\hline & PR2 & - & - & 0.92 & 30 \\
\hline & PR3 & $5.8 \pm 0.8$ & 0.40 & $<0.001$ & 30 \\
\hline & PRcub & $2.3 \pm 0.5$ & 0.17 & $<0.05$ & 30 \\
\hline
\end{tabular}

\section{Discussion}

In this study we have used the MLR and PR approaches to assess what portion of the distribution of a biogeochemical variable is related to the conservative

TABLE 4. As in Table 2, but for $\Delta$ AOU with $\Delta \mathrm{NO}_{3}$.

\begin{tabular}{llcccc}
\hline \hline \multirow{5}{*}{$\Delta \mathrm{AOU}-\Delta \mathrm{NO}_{3}$} & & & \\
\hline Water strata & Approach & Slope & adj- $r^{2}$ & $p$ value & $n$ \\
\hline Ocean interior & MLR & $8.0 \pm 0.1$ & 0.95 & $<0.001$ & 376 \\
& PR2 & $8.0 \pm 0.1$ & 0.94 & $<0.001$ & 376 \\
& PR3 & $8.0 \pm 0.1$ & 0.92 & $<0.001$ & 376 \\
& PRcub & $7.0 \pm 0.1$ & 0.84 & $<0.001$ & 376 \\
Central & MLR & $8.1 \pm 0.1$ & 0.97 & $<0.001$ & 100 \\
& PR2 & $8.4 \pm 0.1$ & 0.97 & $<0.001$ & 100 \\
& PR3 & $8.3 \pm 0.2$ & 0.94 & $<0.001$ & 100 \\
& PRcub & $7.7 \pm 0.2$ & 0.87 & $<0.001$ & 100 \\
Intermediate & MLR & $7.4 \pm 0.1$ & 0.96 & $<0.001$ & 107 \\
& PR2 & $7.4 \pm 0.1$ & 0.95 & $<0.001$ & 107 \\
& PR3 & $7.4 \pm 0.1$ & 0.94 & $<0.001$ & 107 \\
& PRcub & $6.5 \pm 0.3$ & 0.77 & $<0.001$ & 107 \\
& & & & \\
& MLR & $6.5 \pm 0.3$ & 0.61 & $<0.001$ & 133 \\
& PR2 & $7.5 \pm 0.3$ & 0.75 & $<0.001$ & 133 \\
& PR3 & $8.0 \pm 0.2$ & 0.88 & $<0.001$ & 133 \\
& PRcub & $6.7 \pm 0.2$ & 0.83 & $<0.001$ & 133 \\
& MLR & $9.0 \pm 1.3$ & 0.36 & $<0.001$ & 36 \\
& PR2 & $4.7 \pm 0.5$ & 0.63 & $<0.001$ & 36 \\
& PR3 & $9.0 \pm 0.8$ & 0.70 & $<0.001$ & 36 \\
& PRcub & $6.0 \pm 0.2$ & 0.94 & $<0.001$ & 36 \\
\hline \multirow{5}{*}{ Bottom } & & & & &
\end{tabular}



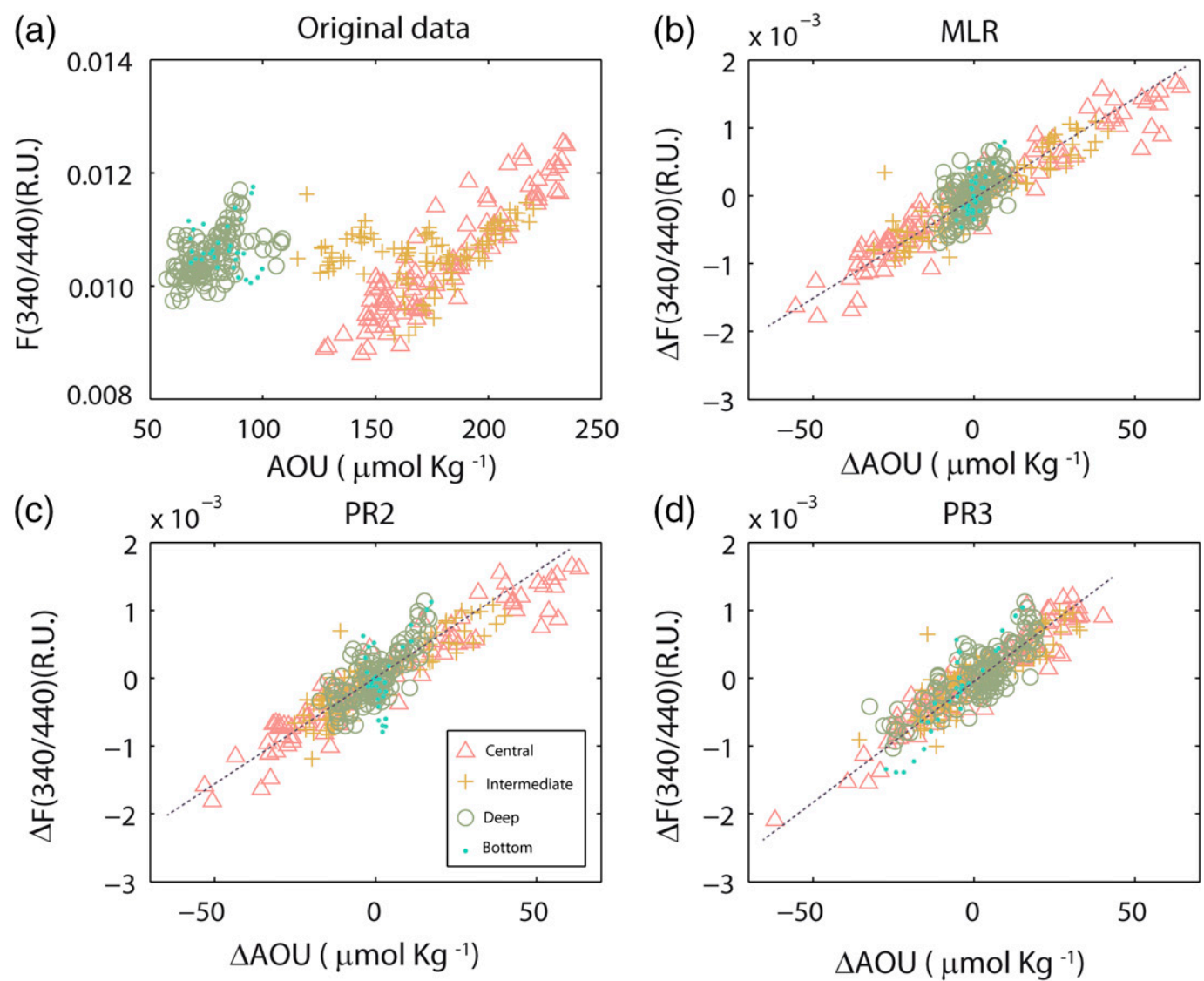

FIG. 4. Scattered plots for the biogeochemical variables: (a) F(340/440)-AOU using the original data; $\Delta F(340 / 440)-$ $\triangle$ AOU after using the (b) MLR, (c) PR2, and (d) PR3 approaches, with the regression lines ( $p$ value $<0.05$; dotted gray lines). The different water strata are indicated: central waters (red triangles), intermediate waters (orange crosses), deep waters (gray circles), and bottom waters (blue dots).

thermohaline properties, that is, to examine what fraction corresponds to the water properties at origin. The differences between the modeled values and the observations are hence identified as biogeochemical anomalies. Both the MLR and PR approaches involve regressions for the nonconservative variables as a function of $\theta$ and $S$ over the entire $(\theta, S)$ space. However, the MLR method uses a linear regression over a confined three-end-member mixing domain, while the PR method uses a nonlinear and global regression.

The general good agreement between the MLR and PR models is an important result, showing that the PR models may replace the classical MLR methods. Its relevance arises because the PR method has no constraint or subjective criterion in the selection of the water masses involved in the conservative mixing. Further, the behavior of PR3 for the deep and bottom strata represents a substantial improvement in the quality of the results.

The MLR method requires identifying the water masses involved in the conservative mixing (i.e., end-member water mass definition and mixing triangles), which is often a difficult task (Carlson et al. 2010; Castro et al. 2006; Li and Peng 2002; Nieto-Cid et al. 2005). Further, in the MLR approach, the thermohaline characteristics arise from a set of vertically ordered mixing triangles, where any data point has to be inside a triangle delimited by three end-members in the $(\theta, S)$ plane. These assumptions cause two principal limitations in the MLR predictive skill of a biogeochemical variable $Y$ that directly affect the anomalies. First, any forecast is a linear combination of three water types, with the outcome depending heavily on the end-member definitions that set the data clusters. Second, the predictions are segmented into distinct subgroups, with artificial ocean boundaries or discontinuities in the $(\theta, S, Y)$ space (Mamayev 1975; Tomczak 1981; Pérez et al. 1998; You 2002).

In contrast with the MLR method, the PR approaches allow high-order (nonlinear) dependences of the biogeochemical variables on both $\theta$ and $S$. One should keep in mind that water masses have preferential oceanic pathways along constant density surfaces. Therefore, 

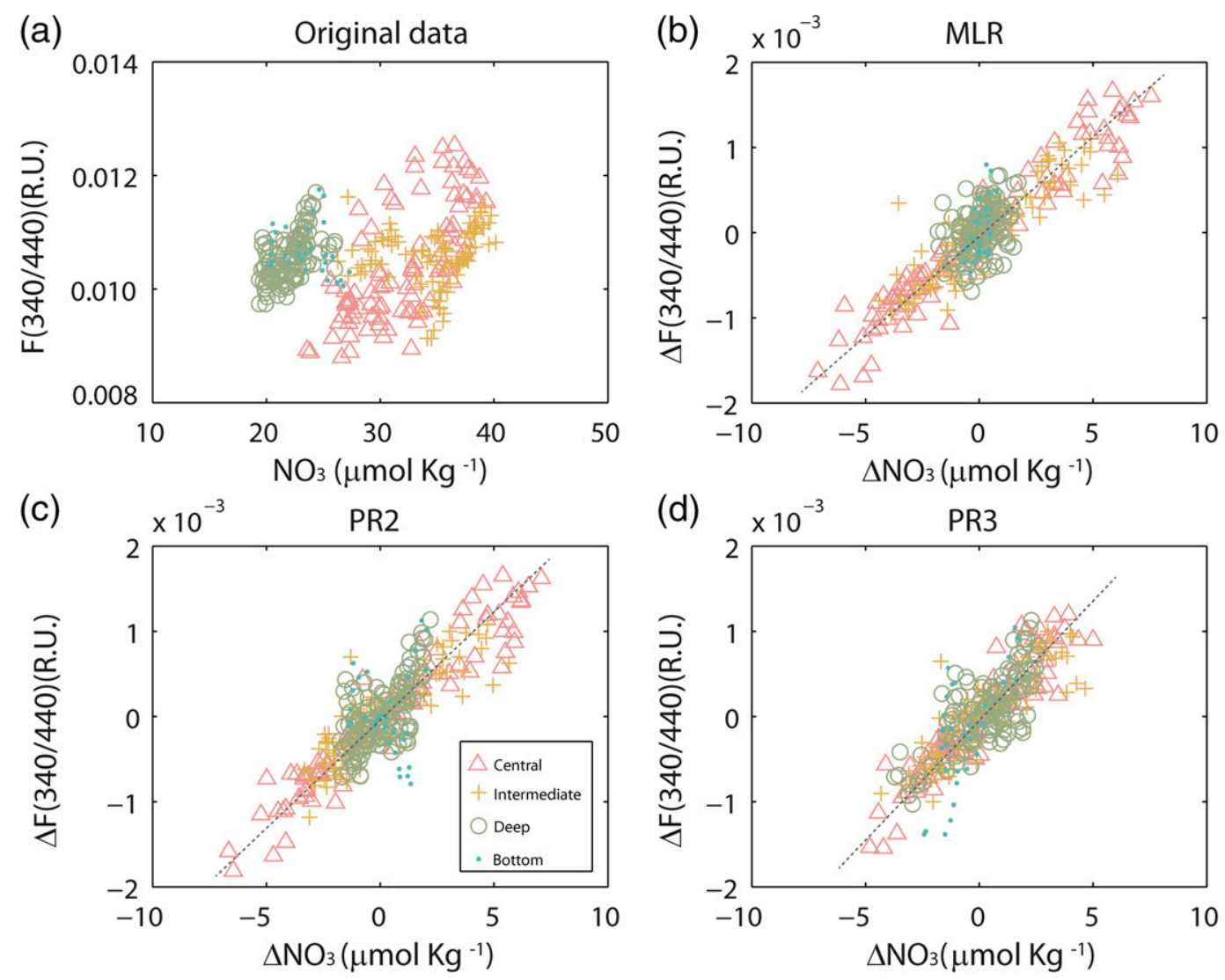

FIG. 5. Scattered plots as in Fig. 4, but for $\mathrm{F}(340 / 440)-\mathrm{NO}_{3}$.

since density displays a nonlinear dependence with temperature and salinity (the equation of state), we may expect that the water masses will not mix linearly in the $\theta-S$ space, in contrast to the mixing triangle concept. Actually, it is remarkable that the PR3 method has terms with the same temperature and salinity dependences as the leading terms in the equation of state, in consonance with the idea that the predominant mixing of biogeochemical variables occurs along isopycnal surfaces. Recently, several works have pointed out the importance of these nonlinear dependences in the context of the global overturning circulation (Klocker and McDougall 2010; Nycander et al. 2015).

In terms of the anomaly correlation slopes and coefficients, the MLR, PR2, and PR3 methods give similar results for either the entire or the surface/intermediate fractions of the water column (Figs. 4-6), but PR3 provides higher correlation coefficients for the deep and bottom waters (Tables 2-4). The largest differences among the methods correspond to the bottom waters: PR2 leads to anomaly scattered plots that have the same pattern as the original data [especially for $\Delta \mathrm{F}(340 / 440)-\Delta \mathrm{NO}_{3}$ where the correlation is nonsignificant], while both MLR and PR3 show significant correlations among anomalies, although the range of values is smaller for MLR than for PR3 (Figs. 7 and S2 in supplemental materials).

We have also explored another polynomial modelPRcub-which retains all terms up to third order except the $S^{3}$ term. This model shows high skill replicating the biogeochemical variables. However, the associate anomalies bear relatively low linear correlation, hence indicating that the model removes most of the nonconservative signal. This particular instance points to the importance of the second methodological step-the analysis of the anomalies-when selecting the most adequate polynomial regression model.

These results strongly suggest that MLR, PR2, and PR3 do equally well for the surface and intermediate strata, and they indicate that PR3 does better in the deep and bottom waters, identifying the conservative fraction much better than PR2 and yet conserving the biogeochemical signal better than MLR (i.e., a local mixing triangle can fit the predictions very well to the data so the anomalies lose their nonconservative signal). Further, the PR3 method appears capable of unraveling the eastern and western bottom water masses (separated by the 

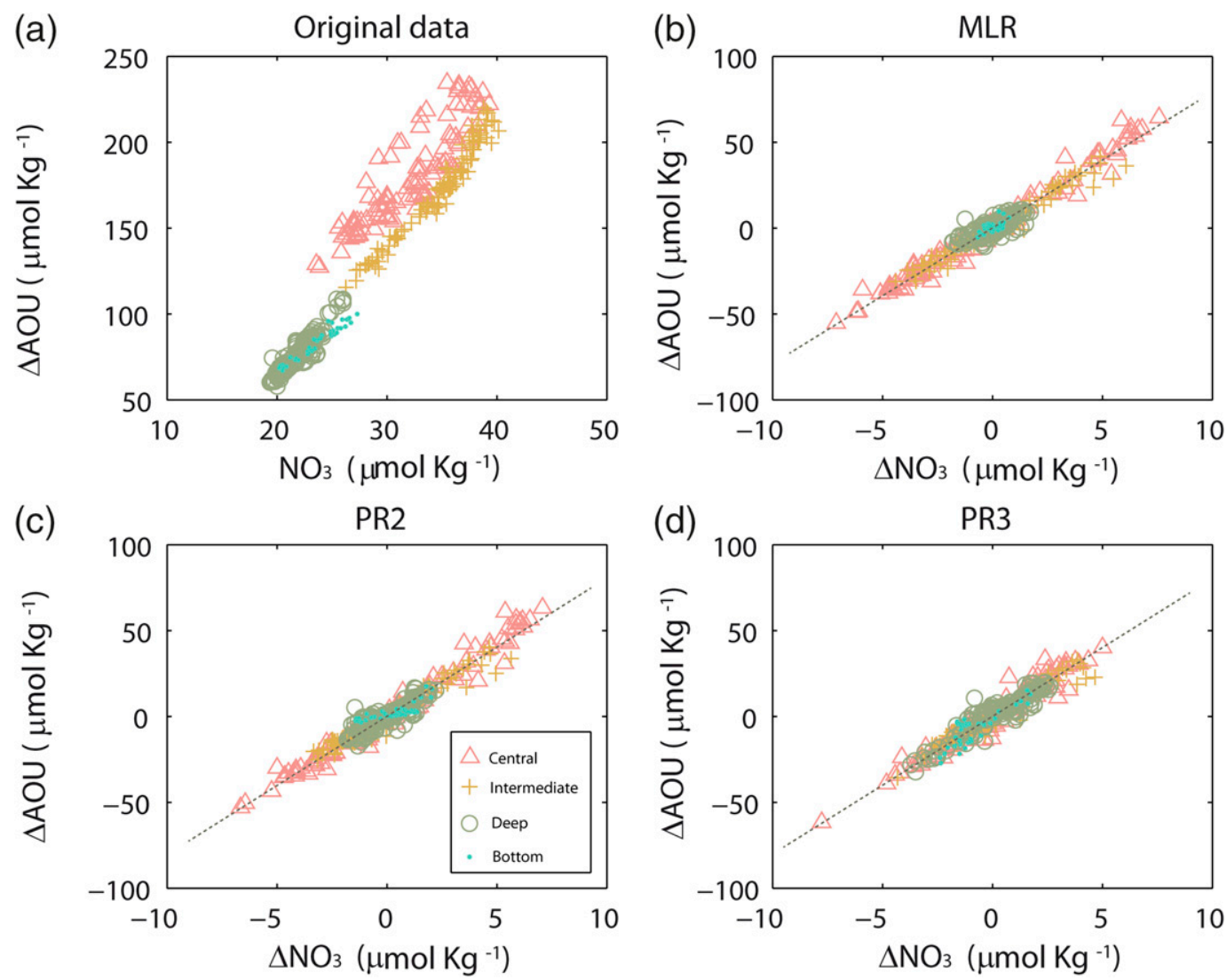

FIG. 6. Scattered plots as in Fig. 4, but for $\mathrm{AOU}-\mathrm{NO}_{3}$.

Mid-Atlantic Ridge) (Figs. 7 and S2 in supplemental materials). The anomaly linear regression is set predominantly by the data in the eastern basin, influenced by the African upwelling where major remineralization processes take place (Peña-Izquierdo et al. 2015). The data from the western basin shows little dependence of the $\mathrm{F}(340 / 440)$ anomalies on $\mathrm{NO}_{3}$ and $\mathrm{AOU}$, probably as a consequence of input of humic-organic-matter sediments.

Our results have shown that the humic-organic-matter PR method, originally used to study the FDOM distributions in the deep ocean (De La Fuente et al. 2014), has good skill at distinguishing between the conservative and nonconservative contributions to biogeochemical variables. The method has two main advantages: conceptual (as nonlinear mixing is allowed) and operative (as it does not require identifying mixing triangles). The potential of the method has also been illustrated with the AOU and $\mathrm{NO}_{3}$ concentrations, rendering an oxygen-nitrogen Redfield ratio close to values reported in the literature. It is important to note that the biogeochemical properties mix as temperature and salinity (this is why we can make the regression), but their values at origin ought to be independent [see the discussion at the beginning of the methods section (section 3)]; if these water type properties depend on temperature and salinity, then the method may not work. This is precisely what happens (not shown) if we apply the PR method directly to dissolved oxygen, as this quantity has a complex nonlinear dependence on both $\theta$ and $S$. This limitation is removed when we work with the AOU, simply because we are removing the oxygen saturation at origin.

\section{Conclusions}

We have presented a simple objective methodology for resolving the nonconservative fraction of biogeochemical variables. Briefly, it first models the data with a nonlinear temperature and salinity polynomial and then calculates the anomalies as the difference between observation and prediction. Our main contribution has been to show that the polynomial regression can produce a fit to data in the entire domain that is as good as or better than a classical local linear mixing approach, and to illustrate that the best polynomial is not one that produces the best data fit but one that leads to anomalies that are highly correlated. This is based on the idea that 

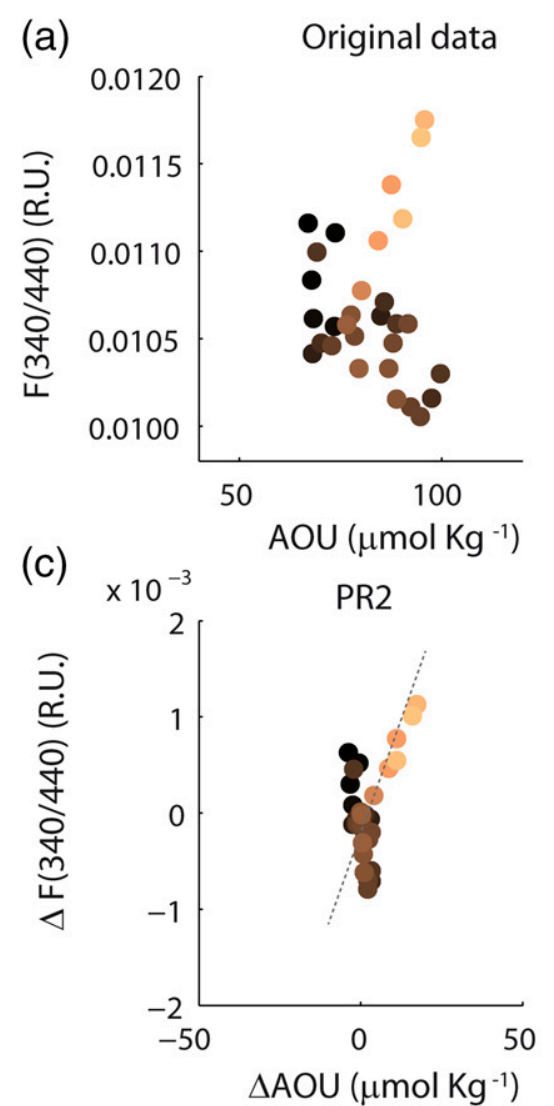

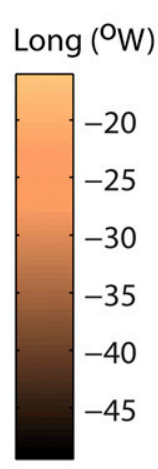

(b) $\times 10^{-3}$

MLR
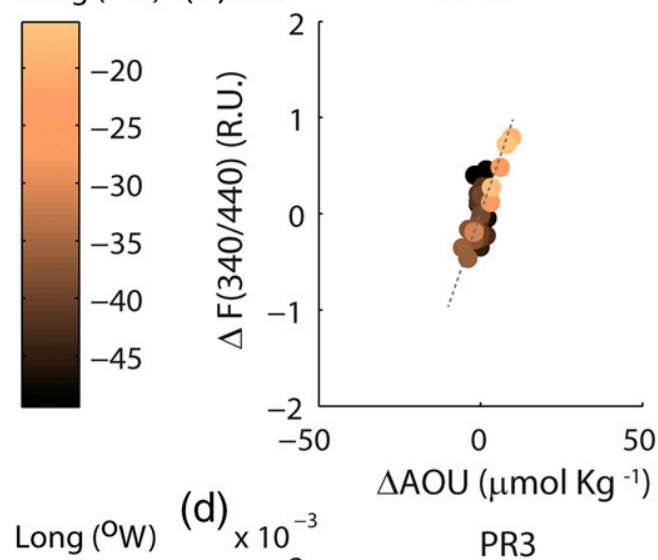

(d)
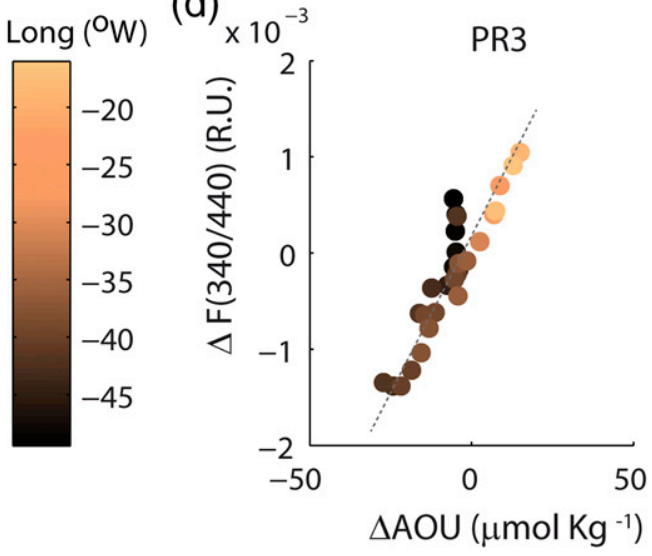

Long ( $\left.{ }^{\circ} \mathrm{W}\right)$

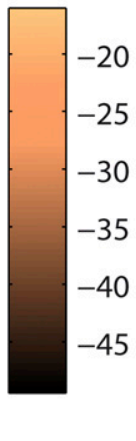

Long ( $\left.{ }^{\circ} \mathrm{W}\right)$

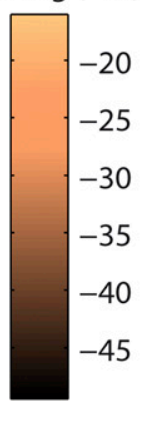

\section{$-35$}

$-40$

$-45$

FIG. 7. Scattered plots for F(340/440)-AOU as in Fig. 4, but only for the data points within the bottom water stratum and the color code indicating the longitude of the water sample.

a high correlation between different property anomalies is the outcome of one or several biogeochemical processes simultaneously acting on all properties.

The traditional multiple linear regression (MLR) approach assumes that any water parcel results from the linear combination of up to three water types and hence the conservative fraction of its biogeochemical properties retains this same linear combination. Here, instead, we have assumed that a water parcel results from the nonlinear mixing of an undefined number of water masses, which is expressed through a polynomial function in terms of both $(\theta, S)$, what we have named the polynomial regression (PR) approach.

We have explored the behavior of the MLR as well as several versions of the PR. A high-order polynomial (PRcub) produces the best fit (in terms of statistical criteria and AIC) to the observations. However, the adjustment is so good that the anomalies lose their nonconservative signal, as shown by the low correlation between related biogeochemical properties. Contrarily, MLR and two polynomials of relatively low order (PR2 and PR3) have lower adjustment to the biogeochemical data but lead to anomalies that bear much higher correlation.

Considering the entire water column of the equatorial North Atlantic, we find that the PR3 biogeochemical anomalies are well correlated, as good as for MLR and better than for a quadratic polynomial (PR2). For each individual stratum, the major discrepancy between the results from the MLR and PR approaches occurs in deep waters and particularly in bottom waters, where PR3 does substantially better than either PR2 or MLR; further, within each of these water strata, PR3 retains a larger range of variations than MLR, suggesting that the latter approach removes some of the nonconservative fraction.

The PR3 methodology also shows good potential for complementary calculations. One example is its ability to identify differences in behavior within the western and eastern Atlantic basins, which may be related to the resuspension of sedimentary organic matter to the west versus the intense biogeochemical processes to the east. Another remarkable instance is its good skill in calculating Redfield regeneration ratios. 
The proposed methodology renders a simple and objective way to identify the nonconservative anomalies for any ocean biogeochemical variable. For our transoceanic cruise in the equatorial North Atlantic, the optimum predictor of the conservative fraction of a biogeochemical variable corresponds to a PR cubic in temperature, linear in salinity, and with one single nonlinear term, but this may change for other regions. Once the particular polynomial is obtained, the spatial and/or temporal distribution of both physical and biogeochemical contributions can be easily calculated, lending information not only on the biogeochemical processes and stoichiometric ratios but also on the patterns of connectivity within a certain region.

Acknowledgments. We thank the assistance from the crew and technicians of the R/V Hespérides during the MOC2-Equatorial cruise. We are grateful to Fiz Pérez and Noelia Fajar for the oxygen calculations on board the vessel, and Xosé Anton Álvarez-Salgado for the methodological and scientific advice. This research was supported by the Spanish government through projects MOC2 (CTM2008-06438-CO2) and VA-DE-RETRO (CTM2014-56987-P). Patricia De La Fuente would like to thank the Agència de Gestió d'Ajuts Universitaris i de Recerca de la Generalitat de Catalunya (AGAUR) for its financial support through an FI-AGAUR fellowship.

\section{REFERENCES}

Álvarez, M., S. Brea, H. Mercier, and X. A. Álvarez-Salgado, 2014: Mineralization of biogenic materials in the water masses of the South Atlantic Ocean. I: Assessment and results of an optimum multiparameter analysis. Prog. Oceanogr., 123, 1-23, https://doi.org/10.1016/j.pocean.2013.12.007.

Álvarez-Salgado, X. A., M. Nieto-Cid, M. Álvarez, F. F. Pérez, P. Morin, and H. Mercier, 2013: New insights on the mineralization of dissolved organic matter in central, intermediate, and deep water masses of the northeast North Atlantic. Limnol. Oceanogr., 58, 681-696, https://doi.org/10.4319/ lo.2013.58.2.0681.

Arhan, M., H. Mercier, B. Bourle, and Y. Gouriou, 1998: Hydrographic sections across the Atlantic at $7^{\circ} 30 \mathrm{~N}$ and $4^{\circ} 30 \mathrm{~S}$. Deep-Sea Res. I, 45, 829-872, https://doi.org/10.1016/S0967-0637(98)00001-6.

Benson, B. B., and D. Krause, 1984: The concentration and isotopic fractionation of oxygen dissolved in freshwater and seawater in equilibrium with the atmosphere. Limnol. Oceanogr., 29, 620-632, https://doi.org/10.4319/lo.1984.29.3.0620.

Carlson, C. A., D. A. Hansell, N. B. Nelson, D. A. Siegel, W. M. Smethie, S. Khatiwala, M. M. Meyers, and E. Halewood, 2010: Dissolved organic carbon export and subsequent remineralization in the mesopelagic and bathypelagic realms of the North Atlantic basin. Deep.-Sea Res. II, 57, 1433-1445, https:// doi.org/10.1016/j.dsr2.2010.02.013.

Castro, C. G., F. F. Pérez, S. E. Holley, and A. F. Ríos, 1998: Chemical characterisation and modelling of water masses in the Northeast Atlantic. Prog. Oceanogr., 41, 249-279, https:// doi.org/10.1016/S0079-6611(98)00021-4.

— M. Nieto-Cid, X. A. Álvarez-Salgado, and F. F. Pérez, 2006: Local remineralization patterns in the mesopelagic zone of the
Eastern North Atlantic, off the NW Iberian Peninsula. Deep-Sea Res. I, 53, 1925-1940, https://doi.org/10.1016/j.dsr.2006.09.002.

Catalá, T. S., and Coauthors, 2015: Turnover time of fluorescent dissolved organic matter in the dark global ocean. Nat. Commun., 6 , 5986, https://doi.org/10.1038/ncomms6986.

Chen, R. F., and J. L. Bada, 1992: The fluorescence of dissolved organic matter in seawater. Mar. Chem., 37, 191-221, https:// doi.org/10.1016/0304-4203(92)90078-O.

Coble, P. G., 1996: Characterization of marine and terrestrial DOM in seawater using excitation-emission matrix spectroscopy. Mar. Chem., 51, 325-346, https://doi.org/10.1016/ 0304-4203(95)00062-3.

_ 2007: Marine optical biogeochemistry: The chemistry of ocean color. Chem. Rev., 107, 402-418, https://doi.org/10.1021/ cr050350+.

Culberson, C. H., 1994: Dissolved oxygen. WOCE operations manual, Vol. 3, Section 3.1, Part 3.1.3, Revision 1, WOCE Hydrographic Programme Office Rep. WHPO 91-1, WOCE Rep. 68/91, 15 pp., https://www.nodc.noaa.gov/woce/woce_v3/ wocedata_1/whp/manuals/pdf/91_1/culber2.pdf.

De La Fuente, P., C. Marrasé, A. Canepa, X. A. Álvarez-Salgado, M. Gasser, N. M. Fajar, C. Romera-Castillo, and J. L. Pelegrí, 2014: Does a general relationship exist between fluorescent dissolved organic matter and microbial respiration? The case of the dark equatorial Atlantic Ocean. Deep-Sea Res. I, 89, 4455, https://doi.org/10.1016/j.dsr.2014.03.007.

Hansell, D. A., 2013: Recalcitrant dissolved organic carbon fractions. Annu. Rev. Mar. Sci., 5, 421-445, https://doi.org/10.1146/ annurev-marine-120710-100757.

Hayase, K., and N. Shinozuka, 1995: Vertical distribution of fluorescent organic matter along with $\mathrm{AOU}$ and nutrients in the equatorial Central Pacific. Mar. Chem., 48, 283-290, https:// doi.org/10.1016/0304-4203(94)00051-E.

-, H. Tsubota, and I. Sunada, 1989: Relationships of fluorescence and AOU in three North Pacific water samples. Sci. Total Environ., 81-82, 315-318, https://doi.org/10.1016/ 0048-9697(89)90138-1.

Hedges, J. I., R. G. Keil, and R. Benner, 1997: What happens to terrestrial organic matter in the ocean? Org. Geochem., 27, 195-212, https://doi.org/10.1016/S0146-6380(97)00066-1.

Jørgensen, L., C. A. Stedmon, T. Kragh, S. Markager, M. Middelboe, and M. Søndergaard, 2011: Global trends in the fluorescence characteristics and distribution of marine dissolved organic matter. Mar. Chem., 126, 139-148, https:// doi.org/10.1016/j.marchem.2011.05.002.

Klocker, A., and T. J. McDougall, 2010: Influence of the nonlinear equation of state on global estimates of dianeutral advection and diffusion. J. Phys. Oceanogr., 40, 1690-1709, https://doi.org/ 10.1175/2010JPO4303.1.

Lawaetz, A. J., and C. A. Stedmon, 2009: Fluorescence intensity calibration using the Raman scatter peak of water. Appl. Spectrosc., 63, 936-940, https://doi.org/10.1366/000370209788964548.

Li, Y.-H., and T.-H. Peng, 2002: Latitudinal change of remineralization ratios in the oceans and its implication for nutrient cycles. Global Biogeochem. Cycles, 16, 1130, https://doi.org/10.1029/ $2001 \mathrm{gb} 001828$.

Llanillo, P. J., J. Pelegrí, C. Duarte, M. Emelianov, M. Gasser, J. Gourrion, and A. Rodríguez-Santana, 2012: Meridional and zonal changes in water properties along the continental slope off central and northern Chile. Cienc. Mar., 38, 307-332, https://doi.org/10.7773/cm.v38i1B.1814.

_ J. Karstensen, J. L. Pelegrí, and L. Stramma, 2013: Physical and biogeochemical forcing of oxygen and nitrate changes 
during El Niño/El Viejo and La Niña/La Vieja upper-ocean phases in the tropical eastern South Pacific along $86^{\circ} \mathrm{W}$. Biogeosciences, $\mathbf{1 0}$, 6339-6355, https://doi.org/10.5194/bg-10-6339-2013.

Mackas, D. L., K. L. Denman, and A. F. Bennett, 1987: Least-square multiple tracer analysis of water mass composition. J. Geophys. Res., 92, 2907-2918, https://doi.org/10.1029/JC092iC03p02907.

Mamayev, O. I., 1975: Temperature-Salinity Analysis of World Ocean Waters. Elsevier Scientific, 374 pp.

McDougall, T. J., and P. M. Barker, 2011: Getting started with TEOS-10 and the Gibbs Seawater (GSW) Oceanographic Toolbox. SCOR/IAPSO Working Group 127, 28 pp.

Nieto-Cid, M., J. Gago, and F. F. Pérez, 2005: DOM fluorescence, a tracer for biogeochemical processes in a coastal upwelling system (NW Iberian Peninsula). Mar. Ecol. Prog. Ser., 297, 33-50, https://doi.org/10.3354/meps297033.

Nycander, J., M. Hieronymus, and F. Roquet, 2015: The nonlinear equation of state of sea water and the global water mass distribution. Geophys. Res. Lett., 42, 7714-7721, https://doi.org/ 10.1002/2015GL065525.

Peña-Izquierdo, J., E. van Sebille, J. L. Pelegrí, J. Sprintall, E. Mason, P. J. Llanillo, and F. Machín, 2015: Water mass pathways to the North Atlantic oxygen minimum zone. J. Geophys. Res. Oceans, 120, 3350-3372, https://doi.org/10.1002/2014JC010557.

Pérez, F. F., C. Mouriño, F. Fraga, and A. F. Rios, 1993: Displacement of water masses and remineralization rates off the Iberian Peninsula by nutrient anomalies. J. Mar. Res., 51, 869-892, https://doi.org/10.1357/0022240933223891.

— - A. F. Rios, C. G. Castro, and F. Fraga, 1998: Mixing analysis of nutrients, oxygen and dissolved inorganic carbon in the upper and middle North Atlantic ocean east of the Azores. J. Mar. Syst., 16, 219-233, https://doi.org/10.1016/S0924-7963(97)00108-5.

_- and Coauthors, 2001: Mixing analysis of nutrients, oxygen and inorganic carbon in the Canary Islands region. J. Mar. Syst., 28 , 183-201, https://doi.org/10.1016/S0924-7963(01)00003-3.

Reinthaler, T., X. A. Álvarez Salgado, M. Álvarez, H. M. Van Aken, and G. J. Herndl, 2013: Impact of water mass mixing on the biogeochemistry and microbiology of the Northeast Atlantic Deep Water. Global Biogeochem. Cycles, 27, 1151-1162, https://doi.org/10.1002/2013GB004634.

San Antolín Plaza, M. Á., J. L. Pelegrí, F. J. Machín, and V. Benítez Barrios, 2012: Inter-decadal changes in stratification and double diffusion in a transatlantic section along $7.5^{\circ} \mathrm{N}$. Sci. Mar., 76, 189-207, https://doi.org/10.3989/scimar.03616.19G.

Schneider, B., J. Karstensen, A. Oschlies, and R. Schlitzer, 2005: Model-based evaluation of methods to determine C:N and $\mathrm{N}: \mathrm{P}$ regeneration ratios from dissolved nutrients. Global Biogeochem. Cycles, 19, GB2009, https://doi.org/10.1029/ 2004GB002256.

Stramma, L., and F. Schott, 1999: The mean flow field of the tropical Atlantic Ocean. Deep-Sea Res. II, 46, 279-303, https:// doi.org/10.1016/S0967-0645(98)00109-X.

Takahashi, T., W. S. Broecker, and S. Langer, 1985: Redfield ratio based on chemical data from isopycnal surfaces. J. Geophys. Res., 90, 6907-6924, https://doi.org/10.1029/JC090iC04p06907.

Tomczak, M., Jr., 1981: An analysis of mixing in the frontal zone of South and North Atlantic Central Water off North-West Africa. Prog. Oceanogr., 10, 173-192, https://doi.org/10.1016/ 0079-6611(81)90011-2.

Tréguer, P., and P. Le Corre, 1975. Manuel d'Analyse des Sels Nutritifs dans l'Eau de Mer. Université de Bretagne Occidentale, $110 \mathrm{pp}$.

Warton, D. I., R. A. Duursma, D. S. Falster, and S. Taskinen, 2012: Smatr 3-An R package for estimation and inference about allometric lines. Methods Ecol. Evol., 3, 257-259, https://doi. org/10.1111/j.2041-210x.2011.00153.x.

Weiss, R. F., 1970: The solubility of nitrogen, oxygen and argon in water and seawater. Deep-Sea Res. Oceanogr. Abstr., 17, 721-735, https://doi.org/10.1016/0011-7471(70)90037-9.

Yamashita, Y., and E. Tanoue, 2008: Production of bio-refractory fluorescent dissolved organic matter in the ocean interior. Nat. Geosci., 1, 579-582, https://doi.org/10.1038/ngeo279.

_- A. Tsukasaki, T. Nishida, and E. Tanoue, 2007: Vertical and horizontal distribution of fluorescent dissolved organic matter in the Southern Ocean. Mar. Chem., 106, 498-509, https://doi.org/ 10.1016/j.marchem.2007.05.004.

You, Y., 2002: Dianeutral exchange between intermediate and deep water in the tropical Atlantic. J. Geophys. Res., 107, 3023, https://doi.org/10.1029/2000JC000520.

Zuur, A. F., E. N. Ieno, N. J. Walker, A. A. Saveliev, and G. M. Smith, 2009: Mixed Effects Models and Extensions in Ecology with $R$. Statistics for Biology and Health, Springer, 574 pp., https://doi.org/10.1007/978-0-387-87458-6. 